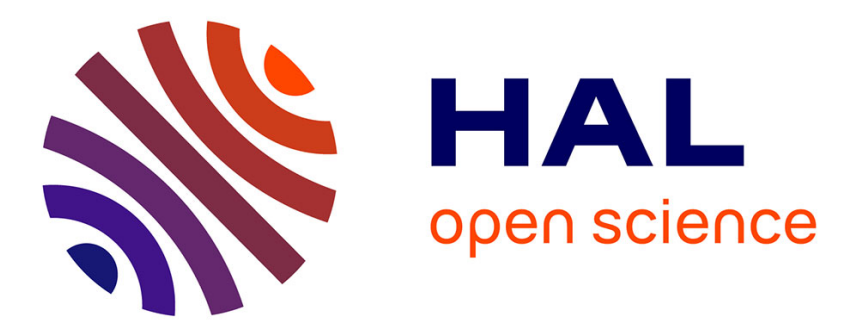

\title{
Comparison between petrophysical properties, durability and use of two limestones of the Paris region
}

Patricia Vázquez, Beatriz Menendez, Mélanie Denecker, Céline Thomachot-Schneider

\section{- To cite this version:}

Patricia Vázquez, Beatriz Menendez, Mélanie Denecker, Céline Thomachot-Schneider. Comparison between petrophysical properties, durability and use of two limestones of the Paris region. The Geological Society, London, Special Publications, 2016, 416 (1), pp.203-216. 10.1144/SP416.15 . hal-02988680

\section{HAL Id: hal-02988680 \\ https://hal.science/hal-02988680}

Submitted on 30 Dec 2021

HAL is a multi-disciplinary open access archive for the deposit and dissemination of scientific research documents, whether they are published or not. The documents may come from teaching and research institutions in France or abroad, or from public or private research centers.
L'archive ouverte pluridisciplinaire HAL, est destinée au dépôt et à la diffusion de documents scientifiques de niveau recherche, publiés ou non, émanant des établissements d'enseignement et de recherche français ou étrangers, des laboratoires publics ou privés. 
Comparison between petrophysical properties, durability and use of two limestones of the Paris region

PATRICIA VAZQUEZ1* , BEATRIZ MENENDEZ2, ME' LANIE F. C. DENECKER2 \& CELINE THOMACHOTSCHNEIDER1

1EA3795 GEGENAA, Universite Reims-Champagne-Ardenne, CREA, 2 esplanade Roland Garros, F1100 Reims, France

2Geosciences et Environnement Cergy, Universite de Cergy-Pontoise, 5, mail Gay-Lussac-Rue d'Eragny, Neuville-sur-Oise, F-95031 Cergy-Pontoise cedex, France

*Corresponding author (e-mail: patricia.vazquez@univ-reims.fr)

Abstract: Most buildings of architectural heritage in Paris and its surroundings are built with Lutetian limestone. Several historic buildings of the 'Vexin Normand' region show Lutetian lime- stone in the upper parts of their walls, while the lower parts are built with a chalk known as 'Pierre de Vernon'. The 'Pierre de Vernon' appears up to the first metre, although in exceptional cases it can reach the middle height of a building. Commonly, chalks exhibit low durability due to their high porosity. However, 'Pierre de Vernon' is supposed to have greater durability than other chalks because of its historic use for basement construction.

The objective of this research was to understand the use of the 'Pierre de Vernon' in the lower part of the constructions. A petrophysical characterization of Vernon chalk and Lutetian limestone was carried out, focusing mainly on the differences in porosity and water uptake. Salt crystalliza- tion tests were done to contrast their response to decay. Colour and roughness measurements and scanning electron microscope observations were performed.

Results show that the different porous networks of these two limestones lead to a high contrast in their hydric properties and responses to decay, and the use of Vernon chalk in the lower sections of buildings has been found to be appropriate.

Several kinds of stone have commonly been used for the construction of historical monuments. The choice of these stones depended not only on socio- economic conditions such as location of the monu- ments and stone quarries, transport facilities and possible funding changes during construction, but also on the characteristics of these stones such as their porous networks and water transfer and mech- anical properties. Furthermore, one variety of stone may have been used for statues and more elaborate parts of the fac,ades, while other varieties may have been mainly used in massive walls. The choice would have depended on the ease with which a stone could be sculpted and on its durability.

Most buildings of architectural heritage in Paris and its surroundings are built with Lutetian limestone, also known as 'Pierre de Paris'. This stone has been used for construction since the Roman 
period. Most of the monuments in Normandy are built with a white Cretaceous chalk with flint nodules known as 'Pierre de Vernon' (Noe"I 1970) or Vernon chalk. Some constructions, such as Rouen Cathedral and several historic buildings of the 'Vexin Normand' region have the characteristic feature of combining these two calcareous stones: Lutetian limestone

and Vernon chalk. These monuments show a distri- bution of the two stones (Blanc 1990): Lutetian limestone is located in the upper part of the walls, while the lower part, from one to several metres in height, has been built with Cretaceous chalk (Fig. 1). Although most Cretaceous chalks might be too porous and friable to be used as building stone, Vernon chalk seems to be sufficiently durable for use in some monuments (Perrier 1993). However, petrophysical studies concerning this building stone are too scarce to confirm its strength and durability. Therefore, the authors assume that Vernon chalk is less permeable than Lutetian limestone and that it could be used in the lower parts of monuments in order to avoid capillary rise.

The objective of this research is to understand, explain and corroborate our hypothesis about the localized use of Vernon chalk. In order to do this, a petrophysical characterization was carried out, focusing on the pore-related differences of both stones. Porosity and hydric properties were measured. Durability was estimated by salt crystallization tests on both types of stone to contrast their response to decay. $\mathrm{Na2SO} 4$ was chosen since it is one of the most damaging salts that often appear in stones exposed outdoors. Its effects are well studied in terms of both subflorescence (Winkler \& Singer 1972; Rodriguez-Navarro \& Doehne 1999; Flatt 2002) and efflorescence (Arnold 1976; Rodriguez-Navarro et al. 2000; Angeli et al. 2010; Va'zquez et al. 2013). $\mathrm{NaCl}$ is a common salt found in building stones exposed close to marine environments (Takiyama et al. 1998; RodriguezNavarro \& Doehne 1999; Gomez-Heras \& Fort 2007). Finally, the SO2 exposure test was performed because it gives information about the adsorption capacity of rocks. Retention capacity of pollutants was one of the presupposed differences between the two stone types. This may lead to the formation of crusts with different morphology and composition (Vazquez \& Alonso 2010; Vazquez et al. 2010; Dewanckele et al. 2012, 2013).

Geology of the two building materials

Lutetian limestone is a very thick formation c. $30 \mathrm{~m}$ high with different levels that also have differ-ent physical properties (Fronteau et al. 2010). The complete stratigraphy can be observed in Figure 2 (after Gely 2009). Only some of the strata can be used as building stone. Samples for this research were selected at the most exploited level i.e. the middle Lutetian. They were quarried and sawed in St Maximin (Rocamat enterprise).

Different commercial designations such as 'Pierre de St Leu', 'Pierre fine', 'liais' and 'Pierre franche' are found in this region. These designations are seen as corresponding to different ages and sedimentation environments. The samples used in the present study correspond to the 'Pierre fine', which is most similar to the stone used in Vexin monuments. 


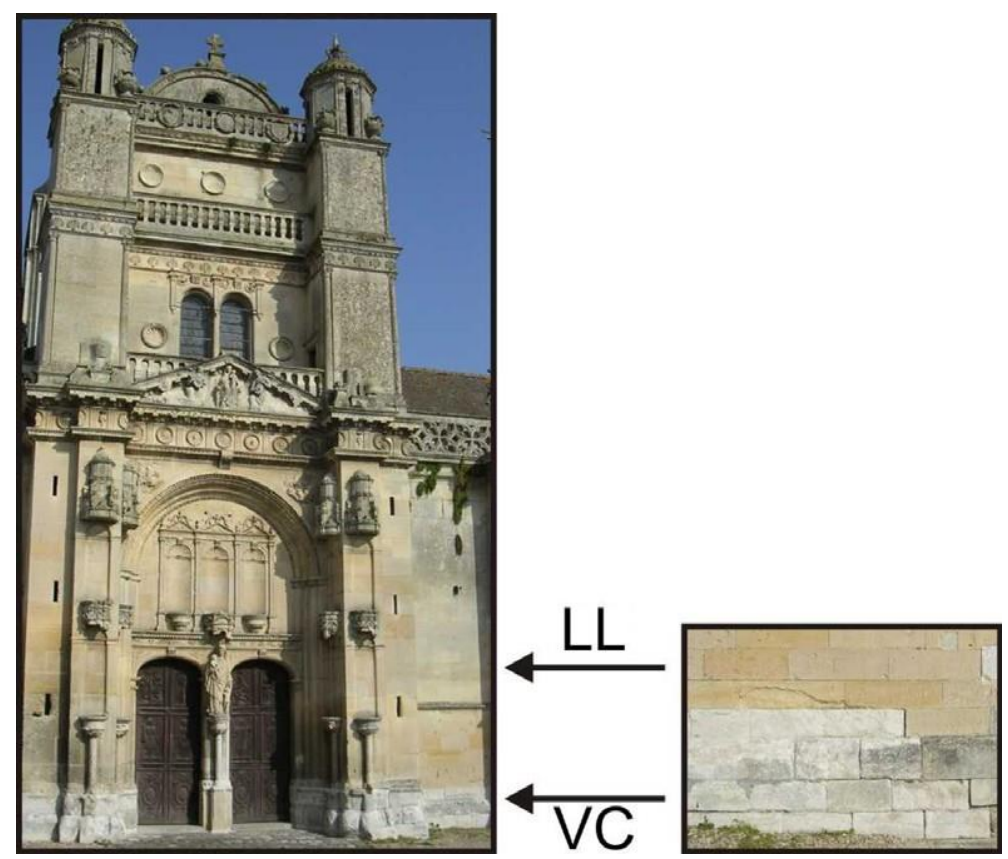

Fig. 1. Facade of Notre Dame de Vetheuil church. The lowest rows of blocks are in Vernon chalk (VC) and the upper rows are in Lutetian limestone (LL).

Vernon stone is a hard white Santonian chalk, probably equivalent to the Newhaven Formation in Great Britain. Vernon quarries exploit two different chalks: 'Banc Franc' and 'Gros lien' (Fig. 3; Blanc 1990; Baboux 1997). The selected samples corre- spond to the 'Gros lien' quarried in the Travaux $d^{\prime}$ 'entretien et de restauration de monuments historiques (TERH) enterprise in Vernon. This stone is used for restoration due to its similarity with those used for the monuments.

Methodology carried out for the comparison

Physical properties

In addition to a petrographic study, different tests were carried out in order to characterize physical properties such as porosity, distribution of the porous space, and the hydric and elastic properties of the two limestones.

The total open porosity was measured using the European standard EN 1936 (CEN 2006) as a reference to the method of triple weighing. The distribution of pore-size access was obtained by mercury injection porosimetry (MIP). Three hydric tests were carried out on the two types of limestone: water absorption capacity using EN13755 (CEN 2008); capillary uptake following EN 1925 (CEN1999); and evaporation by weighing pris- matic samples at regular intervals. The P-wave velocity was measured using a numerical oscilloscope (Handyscope HS3). The experimental device for measurements included a pulse generator from Physical Acoustics Corporation. Transducers had a frequency of $1 \mathrm{MHz}$. 


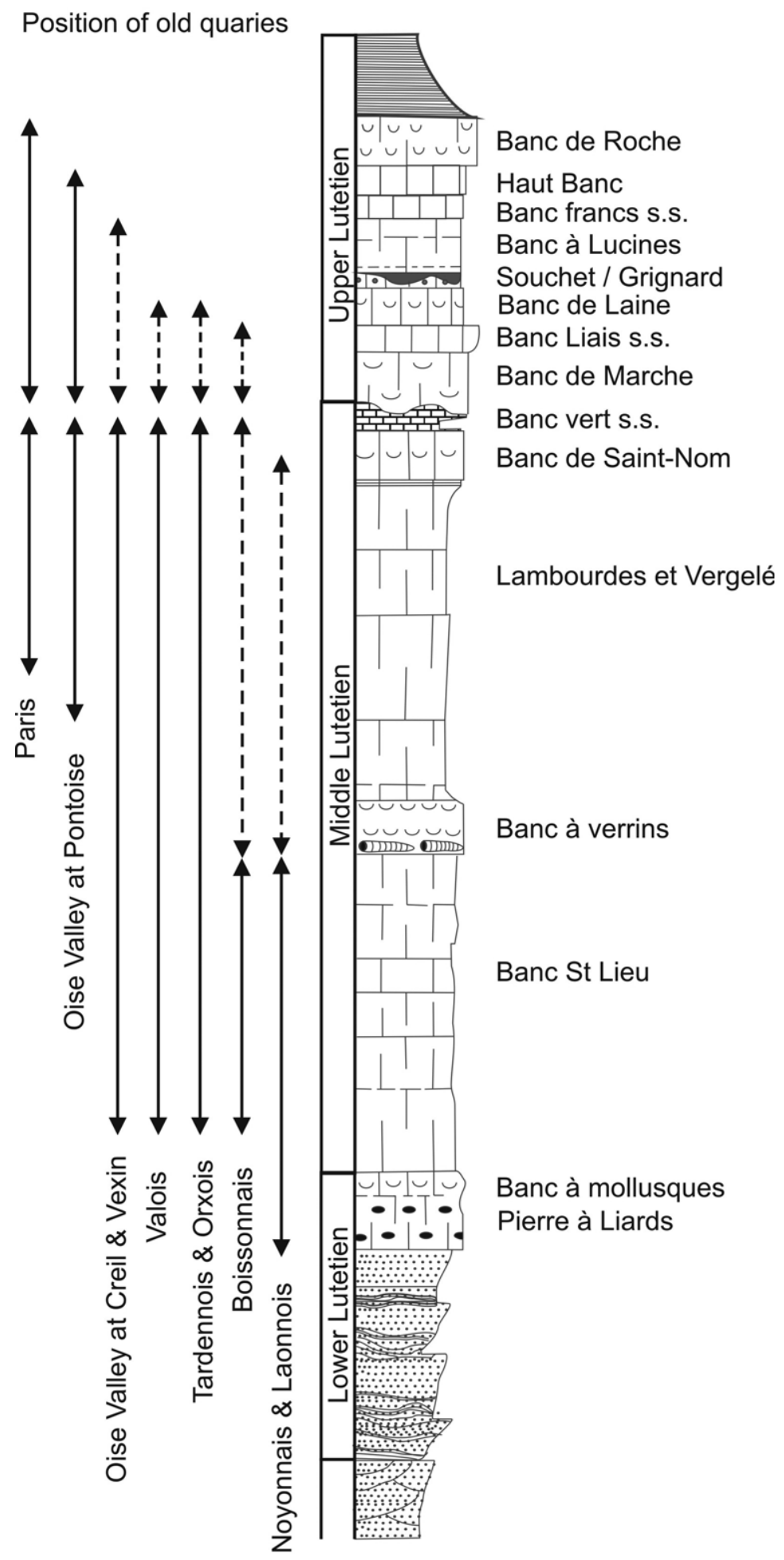

Fig. 2. Lithostratigraphic column of the Lutetian limestone Formation in the Paris area, after Gely (2009). 


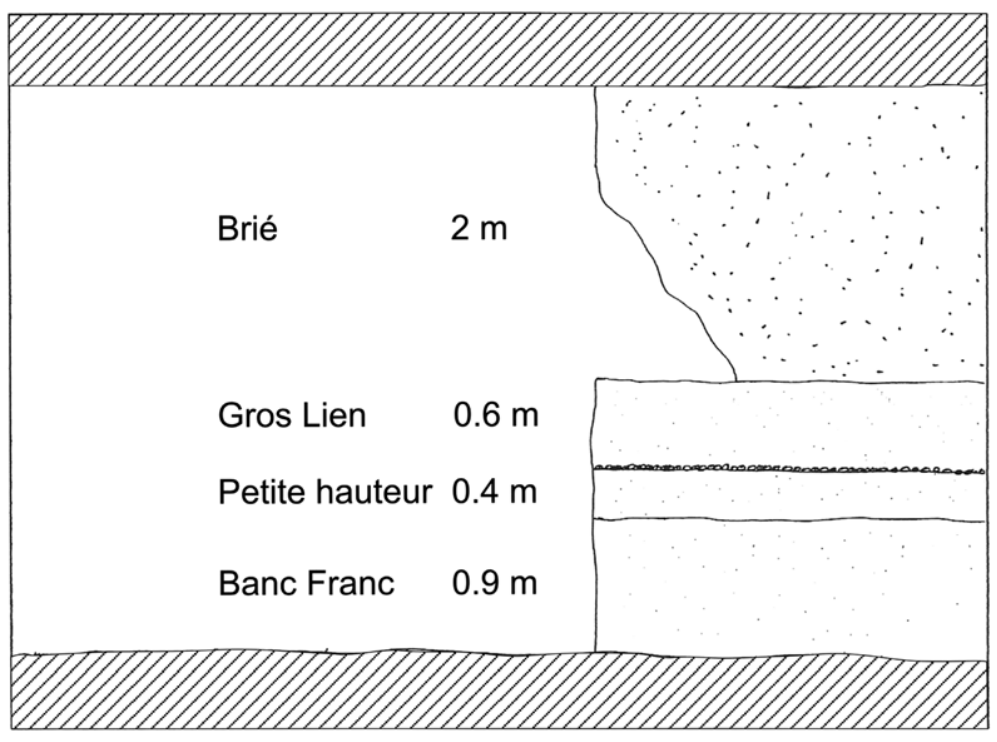

Fig. 3. Schematic distribution of chalk levels used as building stone (the chalk is from the Vernon area quarries), after Blanc (1990) and Baboux (1997).

\section{Durability}

Ageing tests were carried out to compare the differ- ent responses of the two stones to decay. The tests measured resistance to salt crystallization and the effects of exposition to a strong acid atmosphere. The dimensions of the slabs differed depending on the stone and the test. Lutetian limestone speci- mens had been prepared previously with a surface big enough to be exposed and measured. As men- tioned before, Vernon chalk is quarried only for res- toration purposes, so the dimensions of the blocks are limited. Besides, due to the presence of silex nodules, i.e. flints, the heterogeneity of this stone limits the sample dimensions. However, the authors prepared all the slabs to be large enough for their surface properties to be measured in a representative way. All the slabs had a sawed finish.

Salt crystallization test. Six slabs of each stone type were tested. Slabs of Lutetian limestone, dimensions $7 \times 7 \times 1.5 \mathrm{~cm}$, and of Vernon chalk, dimensions $7 \times 4 \times 1.5 \mathrm{~cm}$, were placed in a receptacle with a film of saline solution that rose by capillarity through the porous network. This procedure, carried out under laboratory conditions, closely simulated the real process. The duration of the test was 30 days. Two types of salts were used, $\mathrm{NaCl}$ and $\mathrm{Na} 2 \mathrm{SO} 4$, both at $14 \mathrm{wt} \%$. The standard crystallization test indicates a concentration of $14 \mathrm{wt} \% \mathrm{Na2SO}$, which is much higher than the concentration found in a natural environment. There is no standard for $\mathrm{NaCl}$ crystallization. However, it is well known that the damage produced by this salt is much less than by $\mathrm{Na2SO}$. For this reason the authors decided to use the same concentration for both tests, independently of the initial saturation of the solution. The tests were carried out under labora- tory conditions ( $208 \mathrm{C}$ and $50 \%$ relative humidity) in order to achieve a low evaporation rate and allow the salts to migrate towards the surface. This triggered an initial crystallization of mirabilite as efflorescence, which may dehydrate to thenardite. 
Exposure to polluted atmosphere. Standard EN-13919 (CEN 2002) was taken as reference conceived for the use of $\mathrm{H} 2 \mathrm{SO} 3$ plus $\mathrm{H} 2 \mathrm{O}$ in order to obtain a SO2-rich atmosphere and to allow the formation of a gypsum crust. As in the salt crystallization test, six slabs of each stone type were assessed. Slab dimensions were $4 \times 4 \times 1.5 \mathrm{~cm}$ for Lutetian limestone and $7 \times 4 \times 1.5 \mathrm{~cm}$ for Vernon chalk. Previously, the slabs had been saturated with water at atmospheric pressure. The slabs were placed in a container on a support, $2 \mathrm{~cm}$ over a film of solution so as to avoid direct contact between the surfaces and the solution. The acid sol- ution was made with $50 \mathrm{ml}$ of $\mathrm{H} 2 \mathrm{SO} 3$ and $15 \mathrm{ml}$ of $\mathrm{H} 2 \mathrm{O}$ for a $5 \mathrm{I}$ receptacle; the latter was hermetically sealed and a polluted atmosphere was created. The stones were kept in this environment for 21 days.

Evaluation of changes. The response to the different tests was assessed by macroscopic and microscopic observation. In addition, measurements of colour and roughness of the surface were carried out.

Macroscopic photographs were taken daily to record the slabs' evolution. A scanning electron microscope (SEM) LEICA S430i was used to take detailed images of the surface at the end of the test.

Colour was measured and quantified with a Konika MINOLTA CM-3600d spectrometer using the illuminant D65, beam of diffuse light of $25.4 \mathrm{~mm}$ diameter, 28 viewing angle geometry, and with specular component included. Three aver- aged measurements were done in the centre of the slabs. Data were expressed following the CIE $L^{*} a^{*} b^{*}$ and CIE $L^{*} C^{*} h *$ systems in the standard EN ISO 105-J03 (CEN 2009). DE* was introduced as the total colour change, to compare the variations before and after the tests as follows:$$
\Delta \mathrm{E}^{*}=\sqrt{\Delta \mathrm{L}^{* 2}+\Delta \mathrm{a}^{* 2}+\Delta \mathrm{b}^{* 2}}
$$

Statistical analyses were carried out on the results in order to assess the significance of the variations before and after the cycles.

Surface roughness was measured using a 3D laser-scanning technique. The main component of the 3D laser-digitizing system used in the present study was a laser sensor (ESP3). The laser was attached to a coordinated measuring machine (CMM), which moved the scanner along seven axes. The laser sensor projected a light strip $200 \mathrm{~mm}$ wide on to the surface of the object; this defined a 'laser plane'. The scanners' digital cameras benefited from a true (non-interpolated) resolution of over 1000 points per strip, providing optimum resolution for scanning freeform surfaces and features efficiently. The scanner had an accuracy of $16 \mathrm{~mm}$. An electronic control unit connected the laser sensor, the machine controller for the $\mathrm{CMM}$ and a computer, and processed the signal in real time. A computer program controlled the equipment and processed the generated data to be used for further calculations.

The collected data consisted of 3D non-ordered coordinates, which were stored as ASCII and later handled with SURFERw. The measured points were treated to obtain a regular grid. The interpolation method used was 'krigging' due to the huge quantity of data. The selected spacing between the two closest points in the grid was $50 \mathrm{~mm}$. The grid had $681 \times 681$ profiles and a length of $34 \times 34$ $\mathrm{mm}$. 
This was the maximum area that could be selected after studying each surface individually. The number of data points was c. 465000.

Amplitude surface roughness parameters were calculated following the standard EN ISO 25178 (CEN 2012). The amplitude parameters took into account the vertical characteristics of the surface deviations in relation to an average plane. In this study, calculation of the following parameters was carried out from the points of the grid area and their absolute distance to an average plane:

(1) Sa (arithmetical mean deviation of the surface): it corresponds to the arithmetical mean of the absolute values of the surface deviations from the mean plane and represents the average roughness for each surface.

(2) Sp (maximum area peak height): it corre-sponds to the maximum value of the surface deviations from the mean plane.

(3) Sv (maximum area valley depth): it is the absolute value of the minimum value of the surface deviations from the mean plane.

(4) Smax (maximum height of the area): this is the sum of the highest and the lowest points from the mean plane.

(5) S10 (ten-point height): it corresponds to the different heights between the mean elevations of the five highest peaks and the five deepest valleys of the surface in relation to the mean plane. This parameter is more sensitive to occasional high peaks or deep valleys.

(6) SSk (skewness): it is the third central moment of profile amplitude probability density func- tion, measured over the assessment length. It measures the symmetry of the area about the mean plane. This parameter is highly influ- enced by isolated (occasional) deep peaks or high valleys.

Asymmetrical height distribu- tion has zero skewness. Surfaces with eroded peaks and deep valleys have negative skew- ness, while filled valleys and high peaks have positive skewness.

(7) SKu (kurtosis): it corresponds to the fourth central moment of area amplitude probability density function, measured over the assess- ment length. It describes the sharpness of the probability density of the area. If $\mathrm{Ku}, 3$ the distribution curve is called platykurtic which means few high peaks and low valleys. However, if $\mathrm{Ku} .3$ the distribution curve is called leptokurtic, with many high peaks and deep valleys.

\section{Differences in petrography}

Lutetian limestone is a detritic limestone mainly formed by accumulation of calcite grains and foraminifers of the milioles family (Moreau 2008). This stone has a rough aspect and a light yellowish colour with brownish spots corresponding to ferru- ginous oxides. Macroscopically, numerous small pores can be observed (Noe"I 1970) (Fig. 4a).

Vernon chalk is a white stone that shows small black points of manganese oxide as well as some small flint nodules less than $10 \mathrm{~cm}$ diameter in the layer used for building. These nodules can be much larger in other stratigraphic levels of the Santonian

chalk. The white colour comes from the small content of clay minerals. This stone has suffered a complex diagenetic history through a dolomitization/dedolomitization process. Signals of this process 
are empty rhombohedra on the samples that correspond to precipitation, and later dissol- ution, of dolomite (Fig. 4b). This process is respon- sible for the hardness of the Vernon chalk. A complete study of this chalk can be found in Lasseur (2007).

The microstructure of these two rocks is very different despite them both having a unimodal pore distribution. Lutetian limestone has a detritic structure with ellipsoid grains of c. $100 \mathrm{~mm}$ diam- eter (Fig. 4a). Vernon chalk is mainly a crystalline rock (Fig. 4b). Pores in Lutetian limestone samples are located mainly inside the micritic matrix sur- rounding grains or forming fossils. In Vernon chalk, pores correspond mainly to casts of rhombohedral dolomite crystals but they have access ratios of c. $0.5 \mathrm{~mm}$. This different microstructure controls the pore-size distribution. Pores in Lutetian limestone, excepting macropores undetectable by mer- cury porosimetry, are bigger $(, 20 \mathrm{~mm})$ than pores in Vernon chalk (,1 mm) (Fig. 5). Lutetian lime- stone shows two types of fossils, i.e. milioles and Nummulites. No fossils were observed in Vernon chalk. 
(a1)

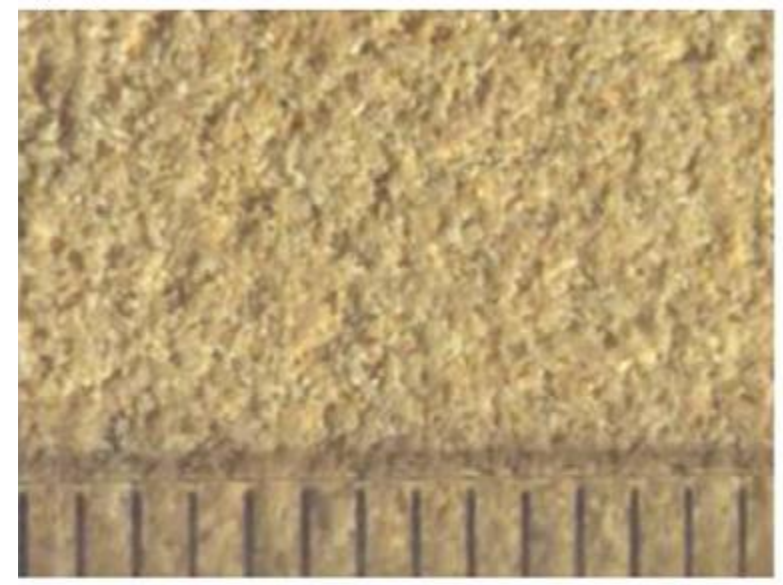

(a2)

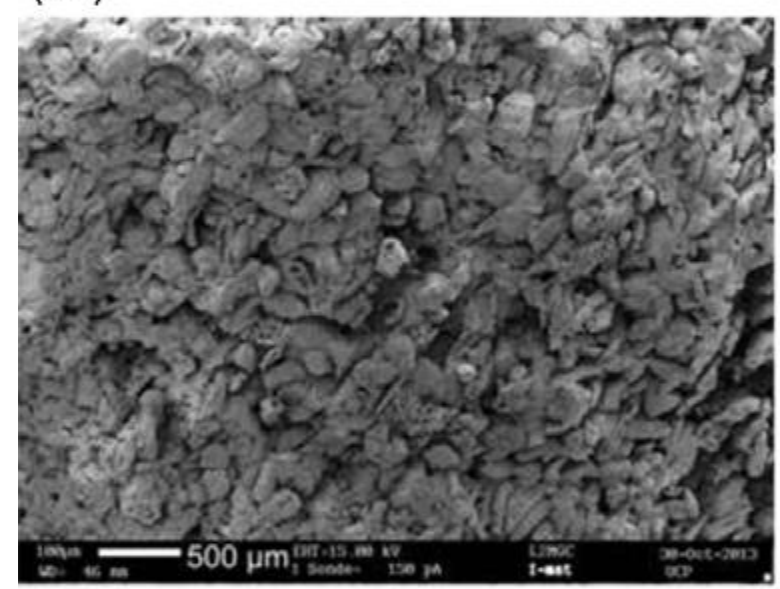

(a3)

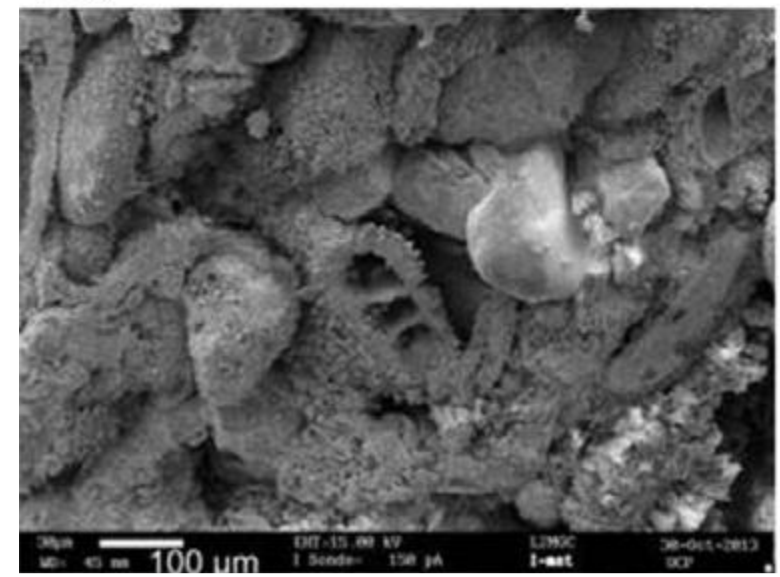

(b1)

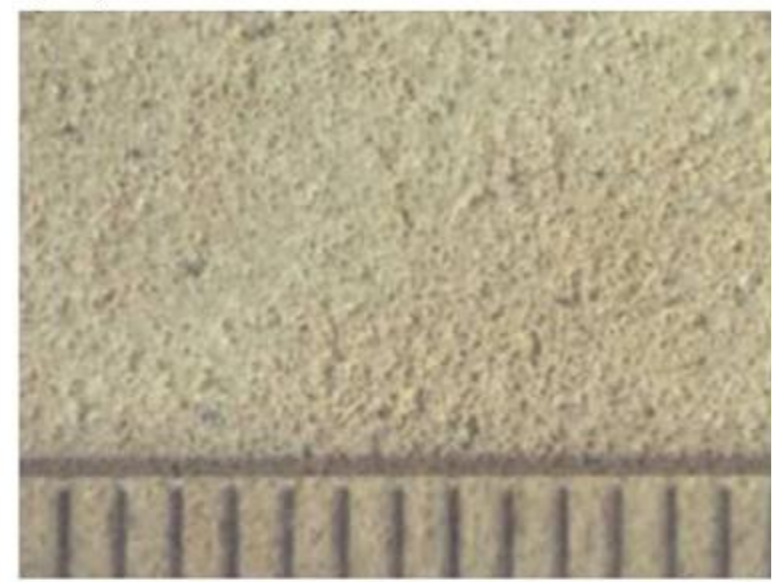

(b2)

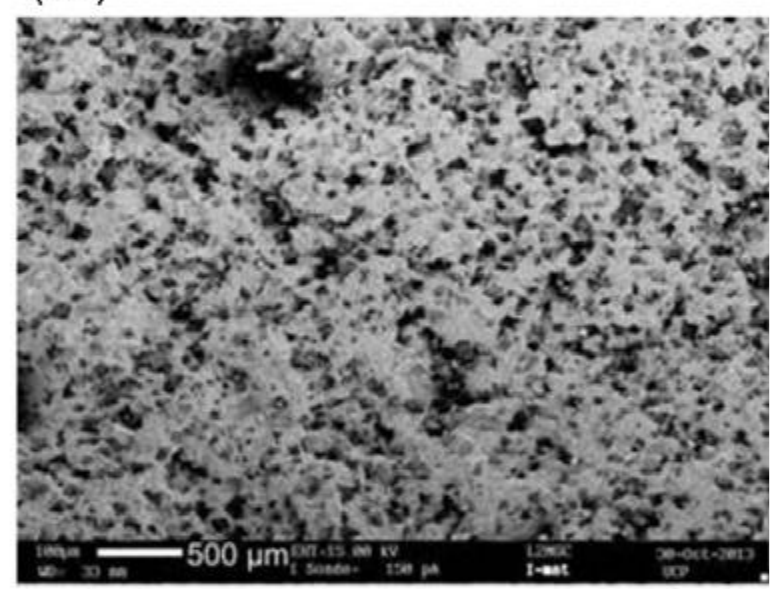

(b3)

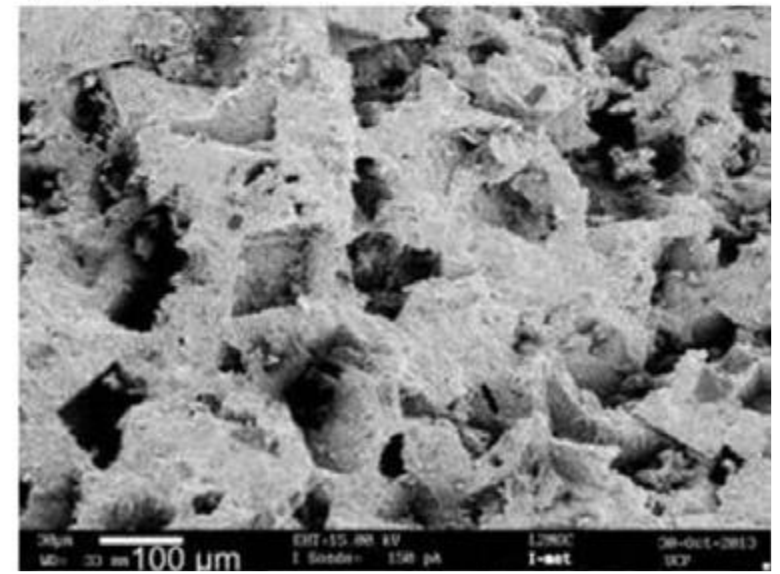

Fig. 4. Images of (a) Lutetian limestone and (b) Vernon chalk, using a magnifying glass (labelled 1) and SEM (labelled $2 \& 3$ ). 


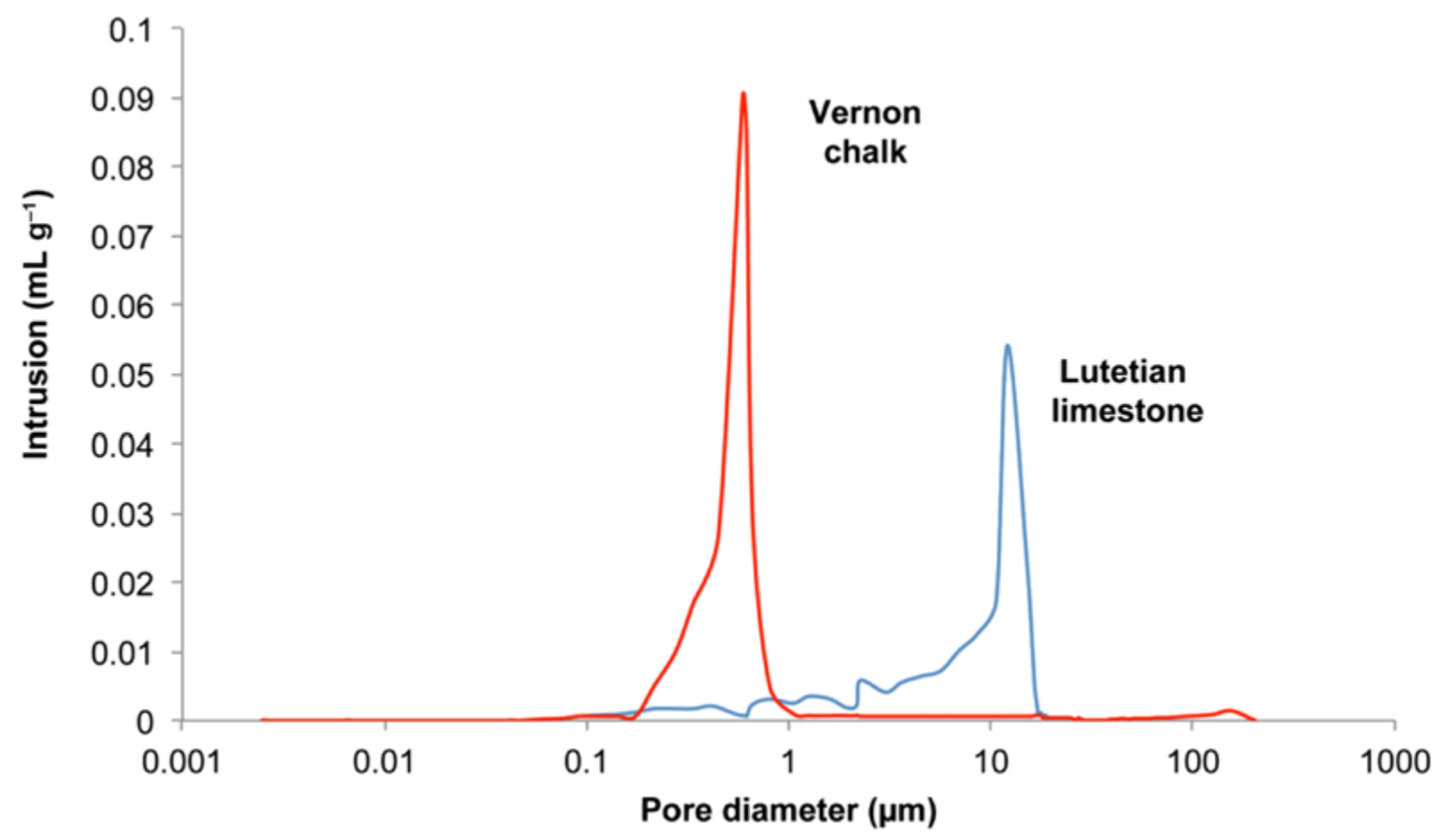

Fig. 5. Pore access distribution obtained by mercury injection porosimetry of Lutetian limestone and Vernon chalk.

Differences in physical properties

Table 1 shows the main values of the physical prop- erties of both stone types. For total open porosity, the Lutetian limestone had the highest values (c. 40\%) whilst theVernon chalk had the lowest (c. $25 \%)$. These porosity values are similar to those obtained by Angeli et al. $(2006,2007)$ and Dessandier (2000) with values of $36.1 \%$ and $35 \%$ respectively for Lutetian limestone, and by Moreau (2008) with $24 \%$ for Vernon chalk. These two limestones showed a different frequency of pore access radii distribution (Fig. 5). In the Lutetian limestone, the pore access radii range mainly between 1 and $20 \mathrm{~mm}$ with a modal peak at $16 \mathrm{~mm}$. These results are consistent with Dessandier (2000) who found a modal peak at $18 \mathrm{~mm}$. The measurements of Vernon chalk gave values of pore access radii between 0.1 and $1 \mathrm{~mm}$ with a peak at $0.6 \mathrm{~mm}$. This prevalence of bigger pores in the Lutetian limestone compared with the Vernon chalk was also reflected in their hydric and dynamic behaviour (Denecker et al. 2013). As can be observed in Figure 6, after three weeks the Lutetian limestone free water absorption capacity, consistent with the value obtained by Denecker (2014), was higher (with $18 \%$ water content) than that of the Vernon stone (6.6\%). However, by that time neither stone had reached stabilization and they both continued gaining weight. The Lutetian limestone absorbed more than $70 \%$ of the total water content during the first 4 min (corresponding to a total water content of c. $13 \%$ ), while the Vernon chalk needed c. $2 \mathrm{~h}$ to reach a linear and slow water uptake and only reached $45 \%$ of its total saturation (corresponding to a total water content of c. 3\%). After these times ( $4 \mathrm{~min}$ and $2 \mathrm{~h}$ respectively), the weight-gain trend was the same for both stones as demonstrated by the parallelism between the line graphs (Fig. 6). After three weeks, the Lutetian limestone reached $85 \%$ saturation against only $60 \%$ in the case of the Vernon chalk. If compared with mercury porosimetry graphs, this faster absorption in the Lutetian limestone can be explained by the majority of pores ranging between c. 1 and $20 \mathrm{~mm}$. Pore access radii in the Vernon chalk was placed c. $0.6 \mathrm{~mm}$ and consequently the water absorption was slower than in the 
Lutetian limestone. After $2 \mathrm{~h}$ both curves were linear and parallel, which meant that smaller pores of similar size were being filled in both stones. Regarding desorption, the Lutetian limestone evaporated $25 \%$ of its water content after one day and $40 \%$ after two days while for the same time the Vernon chalk lost c. $35 \%$ and $60 \%$ of its water respectively. After one week both stones were almost dry.

Table 1. Physical properties of Lutetian limestone and Vernon chalk ( $n \frac{1}{46}$ for both stones)

\begin{tabular}{lccccc}
\hline & $\begin{array}{c}\text { Porosity } \\
(\%)\end{array}$ & $\begin{array}{c}\text { Water saturation } \\
(\%)\end{array}$ & $\begin{array}{c}\text { Capillarity coefficient } \\
\left(\mathrm{g} \mathrm{m}^{-2} \mathrm{~s}^{-1 / 2}\right)\end{array}$ & $\begin{array}{c}\text { Modal pore radius } \\
(\mu \mathrm{m})\end{array}$ & $\begin{array}{c}\text { P-wave velocity } \\
\left(\mathrm{m} \mathrm{s}^{-1}\right)\end{array}$ \\
\hline Lutetien & $40 \pm 3$ & $18.0 \pm 0.5$ & $1215 \pm 120$ & 16 & $2320 \pm 100$ \\
Vernon & $24 \pm 3$ & $6.6 \pm 1.0$ & $40 \pm 10$ & 0.6 & $4380 \pm 130$ \\
\hline
\end{tabular}
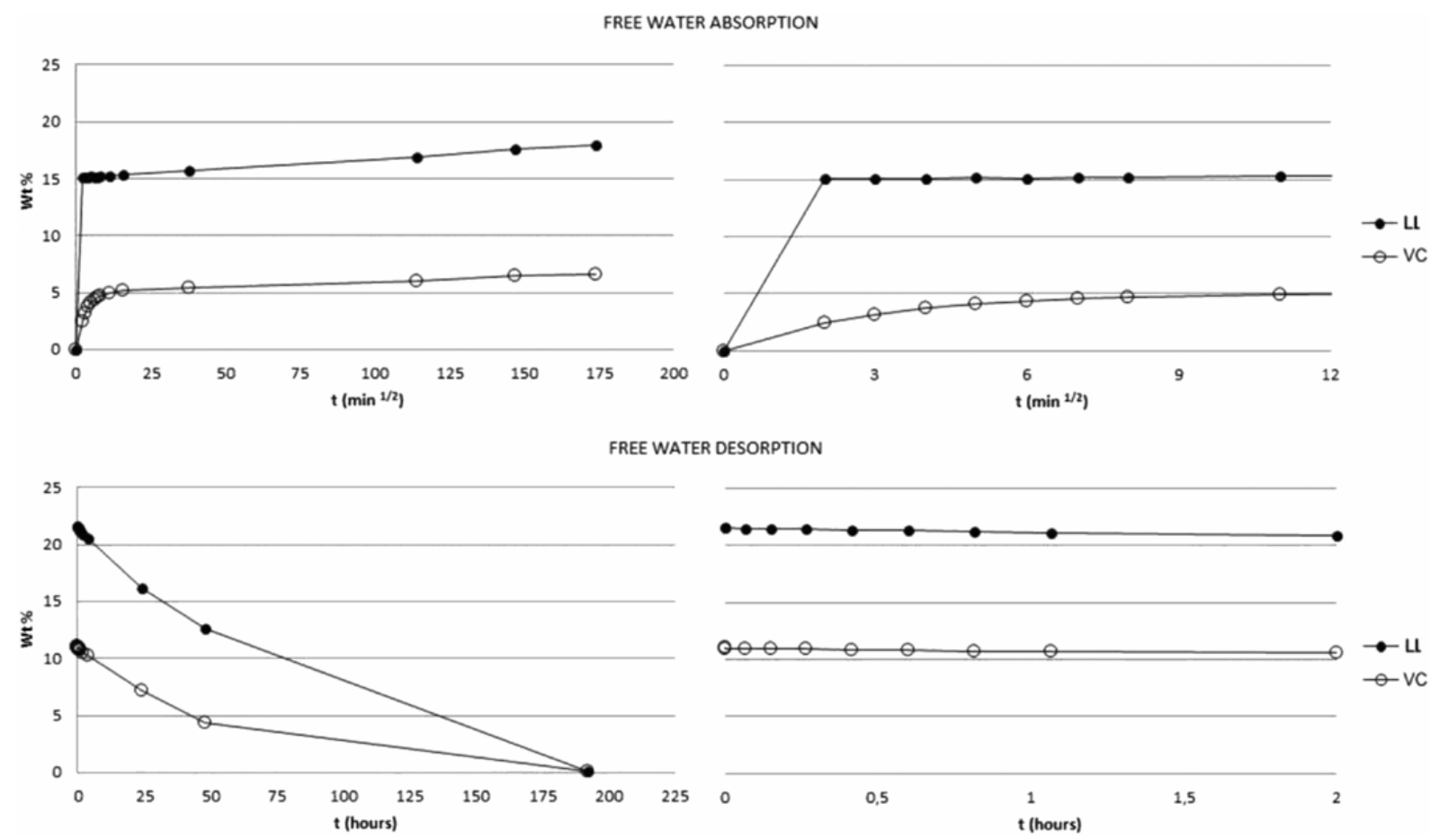

Fig. 6. Water absorption and desorption curves of the two limestones. Wt, water absorption in percentages in relation to time.

The Lutetian limestone had a higher capillarity coefficient than the Vernon chalk, at c. $1200 \mathrm{~g} \mathrm{~m} 22$ $\mathrm{s} 21 / 2$ against $40 \mathrm{~g} \mathrm{~m} 22 \mathrm{~s} 21 / 2$. The Lutetian limestone reached stabilization after $15 \mathrm{~min}$ of capillary uptake while the Vernon chalk needed more than $8 \mathrm{~h}$. Specimens were prisms of area $5 \mathrm{~cm} 2$ and height $15 \mathrm{~cm}$. Water penetration reached $15 \mathrm{~cm}$ in the Lutetian limestone after $15 \mathrm{~min}$ while in the case of the Vernon chalk the maximum height after $8 \mathrm{~h}$ was c. $2 \mathrm{~cm}$. These results agree with those obtained by Angeli (2007) for Lutetian limestone with a coefficient of $1100 \mathrm{~g} \mathrm{~m} 22$ s21/2 and by Moreau (2008) for Vernon chalk with a value of $90 \mathrm{~g} \mathrm{~m} 22 \mathrm{~s} 21 / 2$.

There was an inverse relationship between the P-wave propagation velocities and the samples' porosity. The high porosity of the Lutetian lime- stone was associated with a low P-wave velocity ( $2300 \mathrm{~m} \mathrm{~s} 21$ ) whereas the low porosity of the Ver- non chalk was linked with a high P-wave velocity (around $4400 \mathrm{~m} \mathrm{~s} 21$ ). The P-wave velocity of calcite was c. $6300 \mathrm{~m} \mathrm{~s} 21$ (Carmichel 1989), and the 
corre- lation between porosity and the decrease in P-wave velocity was almost linear. The Lutetian limestone P-wave velocity was slightly lower than the velocity expected from the linear correlation because of impurities in its composition and the big pore size that may interfere negatively in wave propagation. P-wave velocity values for Lutetian limestone are consistent with those obtained by Denecker (2014), with values c. 2540 m s21.

\section{Differences in durability}

Table 2 shows colour parameter values of the sound stones and absolute values of their variation after each test. The statistical significance of the change was obtained by the Mann Whitney $U$ test and is also detailed in the table. Both stones showed high lightness with values above 75 and a slight trend to red with values of $a^{*}$ between 1 and 4 . The main difference lay in yellow parameter $b^{*}$, with values c. 20 in the Lutetian limestone and c. 8 in the Vernon chalk.

Table 3 shows the roughness parameters of the sound stones and their variation after the weathering tests expressed in percentages. In this article, the authors consider a variation of between $25 \%$ and $50 \%$ as 'slight', and higher than $50 \%$ as signifi- cant. Besides allowing for thresholds of change to be established, the expression of the results as per-centages allowed the parameter changes to be com- pared with very different initial values. When the two sound stones were compared, the Lutetian lime- stone showed higher values of roughness parame- ters than the Vernon chalk, mainly due to grain size, porosity and cementation. Average roughness was c. $40 \mathrm{~mm}$ in the Lutetian limestone and $32 \mathrm{~mm}$ in the Vernon chalk which implied a $25 \%$ differ- ence. In both stones, Sp was lower than Sv which can be explained by the sawed finish. Pores are the valleys measured in Sv. The difference in all the par-ameters was related to the maximum roughness (Sp, Sv, S10, Smax) which was c. $65-70 \%$ higher in the Lutetian limestone than in the Vernon chalk. Both sound stones presented a leptokurtic distribution, with Su values greater than 3 . This distribution had a low and wide peak around the mean and thin tails, which means that the extreme values of peaks and valleys were more important than the average deviations. Skewness was negative and similar in both sound stones, which makes the valleys more significant than the peaks. This agrees with the values found in Sp and Sv and is explained by the saw finish of the stones. 
Table 2. Variation in colour parameters

\begin{tabular}{|c|c|c|c|c|c|c|c|}
\hline & & $\mathbf{L}^{*}$ & $a^{*}$ & $\mathbf{b}^{*}$ & $\mathrm{C}^{*}$ & $\mathbf{h}^{*}$ & $\Delta \mathbf{E}^{*}$ \\
\hline \multicolumn{8}{|l|}{ Lutetien } \\
\hline \multirow[t]{2}{*}{$\mathrm{Na}_{2} \mathrm{SO}_{4}$} & Pre & 75.19 & 3.04 & 20.46 & 20.69 & 81.63 & 13.17 \\
\hline & Post $(\Delta)$ & $8.14 *$ & $-1.35^{*}$ & $-10.27 *$ & $-10.36^{*}$ & -1.04 & \\
\hline \multirow[t]{2}{*}{$\mathrm{NaCl}$} & Pre & 74.52 & 3.30 & 20.84 & 21.10 & 81 & 0.80 \\
\hline & Post $(\triangle)$ & -0.51 & -0.02 & -0.62 & -0.61 & -0.18 & \\
\hline \multirow{2}{*}{$\mathrm{SO}_{2}$} & Pre & 74.28 & 3.44 & 21.19 & 21.47 & 80.76 & 0.92 \\
\hline \multirow{2}{*}{\multicolumn{8}{|c|}{ Vernon }} \\
\hline & & & & & & & \\
\hline \multirow[t]{2}{*}{$\mathrm{Na}_{2} \mathrm{SO}_{4}$} & Pre & 76.35 & 1.60 & 8.30 & 8.45 & 79.19 & 6.52 \\
\hline & Post $(\Delta)$ & $5.72 *$ & $-0.66^{*}$ & $-3.06^{*}$ & $-3.13^{*}$ & 0.49 & \\
\hline \multirow[t]{2}{*}{$\mathrm{NaCl}$} & Pre & 77.03 & 1.42 & 8.33 & 8.46 & 80.11 & 2.93 \\
\hline & Post $(\Delta)$ & $-2.66^{*}$ & $0.29 *$ & 1.19 & 1.22 & -0.35 & \\
\hline \multirow[t]{2}{*}{$\mathrm{SO}_{2}$} & Pre & 75.86 & 1.64 & 8.44 & 8.60 & 79.00 & 4.07 \\
\hline & Post $(\Delta)$ & $-3.56 *$ & 0.13 & 1.97 & 1.96 & $1.44 *$ & \\
\hline
\end{tabular}

Colour parameters of sound stones before salt weathering tests (Pre) and their variations in absolute values after the tests $(\operatorname{Post}(\Delta) ; n=18$, i.e. six slabs with three measurements in each slab. Parameters are: L*: Lightness; $a^{*}$ : chromatic parameter from green to red; $b^{*}$ : chromatic parameter from blue to yellow; $\mathrm{C}^{*}$ : chroma; $\mathrm{h}^{*}$ : hue; $\Delta \mathrm{E}^{*}$ : total colour change.

*Statistically significant

\section{$\mathrm{Na} 2 \mathrm{SO} 4$ crystallization test}

Colour. After the test, both stones exhibited the same trend. Lightness increased visibly in the samples (Fig 7) while a* and b* decreased. Conse- quently, $\mathrm{C}^{*}$ decreased as well, which led to a loss in the colour intensity. This was due to the fact that although slab cleaning was done with a soft brush, the salt remained on the surface, giving the stones a whitish aspect. DE* was 13.2 in the Lute- tian limestone and 6.5 in the Vernon chalk. In both cases the total colour variation was consider-ably greater than 3 (the limit of visible change), and this change was corroborated by the visual appearance.

Table 3. Variation in roughness parameters

\begin{tabular}{|c|c|c|c|c|c|c|c|c|}
\hline & $S a$ & $S q$ & $S p$ & $S v$ & $S 10$ & Smax & $S K u$ & $S S k$ \\
\hline \multicolumn{9}{|l|}{ Lutetian } \\
\hline Pre $(\mu \mathrm{m})$ & 41 & 52 & 156 & 342 & 246 & 499 & 4.01 & -0.72 \\
\hline $\mathrm{Na}_{2} \mathrm{SO}_{4}(\%)$ & $74 *$ & $72 *$ & $117 *$ & 25 & $54 *$ & $54 *$ & -13 & 0 \\
\hline $\operatorname{NaCl}(\%)$ & 28 & 29 & 29 & 17 & 22 & 21 & -8 & -48 \\
\hline $\begin{array}{l}\mathrm{SO}_{2}(\%) \\
\text { Vernon }\end{array}$ & $80 *$ & $75^{*}$ & $79 *$ & 21 & 40 & 39 & -30 & -91 \\
\hline Pre $(\mu \mathrm{m})$ & 32 & 40 & 92 & 209 & 148 & 300 & 3.72 & -0.84 \\
\hline $\mathrm{Na}_{2} \mathrm{SO}_{4}(\%)$ & 18 & 20 & $94 *$ & 13 & 36 & 38 & 3 & -7 \\
\hline $\mathrm{NaCl}(\%)$ & $67 *$ & $61 *$ & $93 *$ & -10 & 22 & 22 & -41 & -90 \\
\hline $\mathrm{SO}_{2}(\%)$ & 38 & 37 & $64 *$ & 33 & 43 & 42 & -6 & -15 \\
\hline
\end{tabular}

Surface roughness parameters of the sound stone: values before salt weathering tests (Pre) and their variations (\%) after the tests. Kurtosis (SKu) and Skewness (SSk) are dimensionless.

*Variations $>50 \%$ are considered as 'significant'; variations between $25 \%$ and $50 \%$ are considered as 'slightly significant' 


\section{EFFLORESCENCES AFTER SOFT BRUSHING}
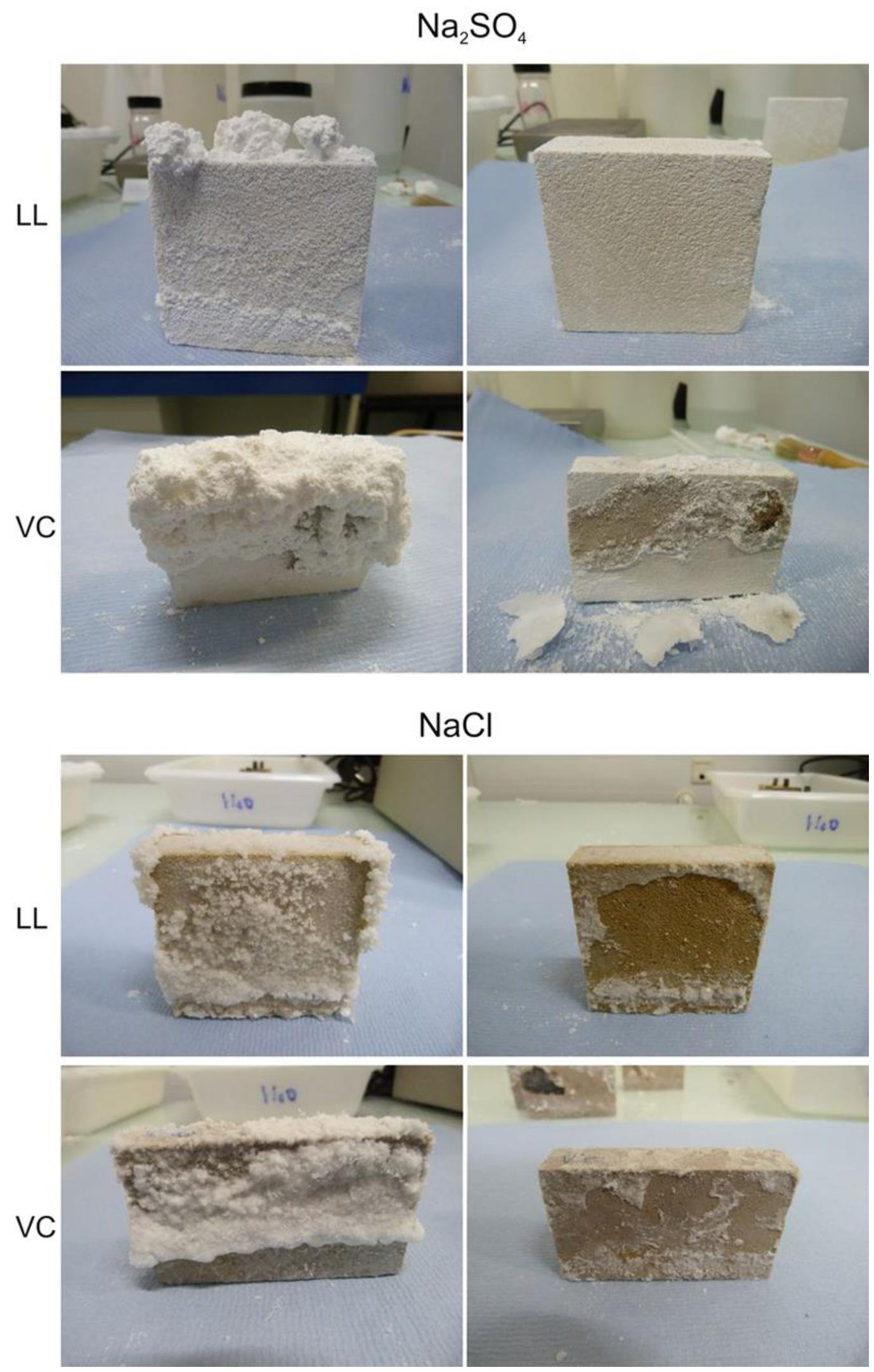

Fig. 7. Visual appearance of slabs of Lutetian limestone (LL) and Vernon chalk (VC) after the salt weathering tests, and after initial soft brushing. Some crusts can be observed; these were only removed if this was possible with no effort. 
Roughness. In general, the Lutetian limestone exhibited greater variation than the Vernon chalk. Sa increased by c. $75 \%$ in the Lutetian limestone against $20 \%$ in the Vernon chalk, and the latter result can be negligible. In both cases, maximum peaks doubled their initial height, while valleys remained almost unchangeable or slightly deeper.

The variation in the peak-valley distribution, defined by kurtosis and skewness, had no significant, or very slight, variation.

Macroscopic and microscopic observations. At the macroscopic scale, efflorescences were remarkable on both stones, starting from the tops of the slabs and growing in all directions. Macroscopic obser- vation after the test revealed a whitening of both stones, without visible mechanical damage. After soft brushing, salt on the surface remained more homogeneously distributed on the Lutetian lime- stone than on the Vernon chalk. In the latter case, when salts were removed, a thin crust remained in contact with the stone. This crust was easily detached without any damage to the stone being visible with the naked eye. No other mechanical changes were noticeable by eye in either stone.

At the microscopic scale, thenardite formed a quite uniform layer of small crystals $(, 5 \mathrm{~mm})$ that covered the grain walls on the Lutetian limestone. On the external surface, this layer of small crystals completely coated the sample surface and sealed the pores (Fig. 8a); this has also been observed by Angeli et al. (2007) for Lutetian limestone where salts partially obstructed the pore openings and cov- ered the calcite grains. On the Vernon chalk, the surface and the subsurface were partially coated with large crystals of thenardite $(.50 \mathrm{~mm})$ giving the appearance of a 'glaze' that filled the squared pores (Fig. 4b: image 2).

\section{$\mathrm{NaCl}$ crystallization test}

Colour. At the end of this test, no significant vari- ation in the Lutetian limestone was observed. DE* was 0.8 which meant a non-visible change. The Ver- non chalk exhibited a slight but significant decrease of lightness and increase of a*. The variation of hue and chroma was not significant, which means that the colour tone and intensity remained almost intact. DE was close to 3 , this being the threshold of visual perception of change.

Roughness. The Lutetian limestone exhibited a general increase of all parameters. The Vernon chalk increased its average roughness and number of peaks. Kurtosis of the Lutetian limestone did not change significantly. Vernon chalk suffered a decrease of almost $50 \%$ at which point the distribution became platykurtic, implying the disappearance of high peaks and deep valleys, leading to a uniform distribution of peaks and valleys. Skewness increased in the Lutetian limestone, defining a diminution of valley depths. This was due to the fact that $\mathrm{NaCl}$ crystallized into the pores, making it difficult to remove by soft brushing alone. In the Vernon chalk, skewness reached values close to zero implying that the distribution of peaks and valleys around the mean plane had equilibrated. The parameters related to maximal roughness ( $\mathrm{S} 10$ and Smax) increased in both stones by c. 20\%. The Lutetian limestone exhibited a similar variation of Sp and Sv, while variations in the Vernon chalk were characterized by a strong increase in $\mathrm{Sp}$ with a redistribution of the mean plane. 
(a)

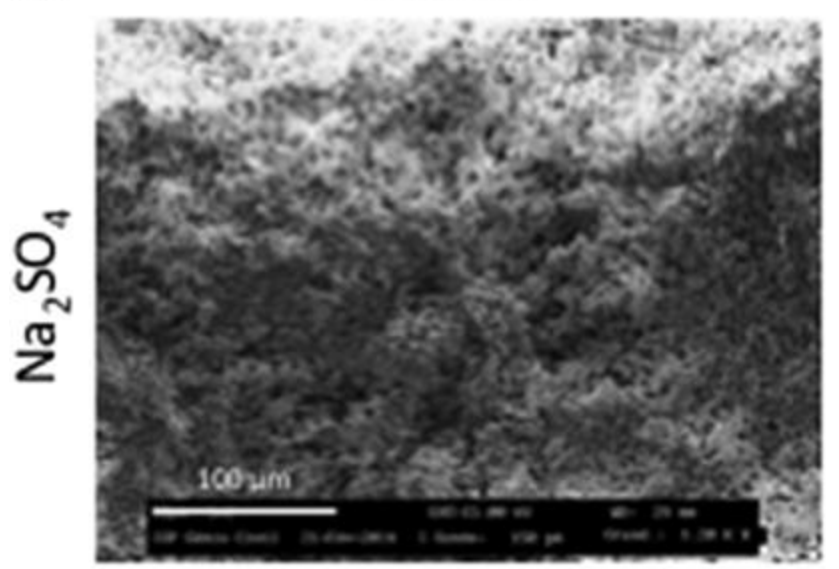

(b)

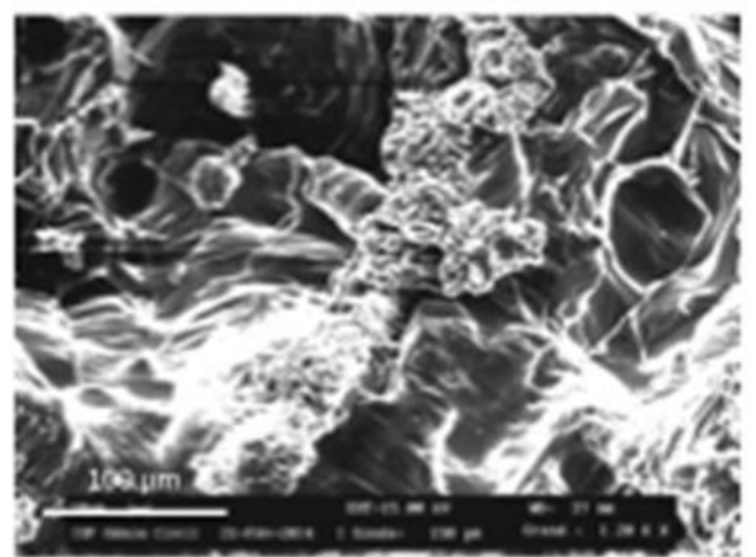

(c)

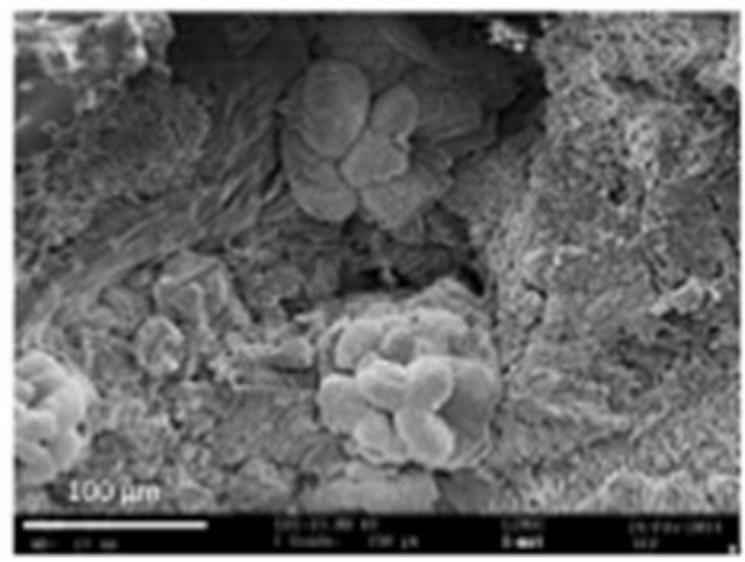

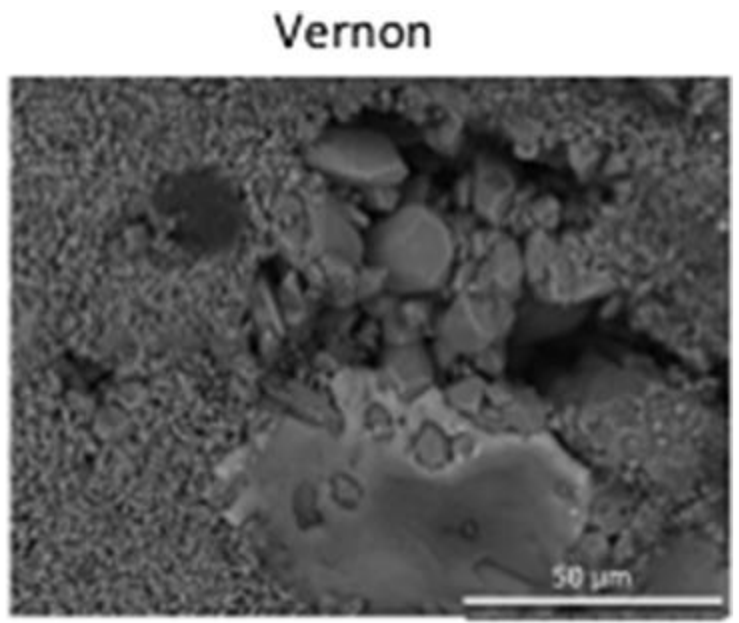
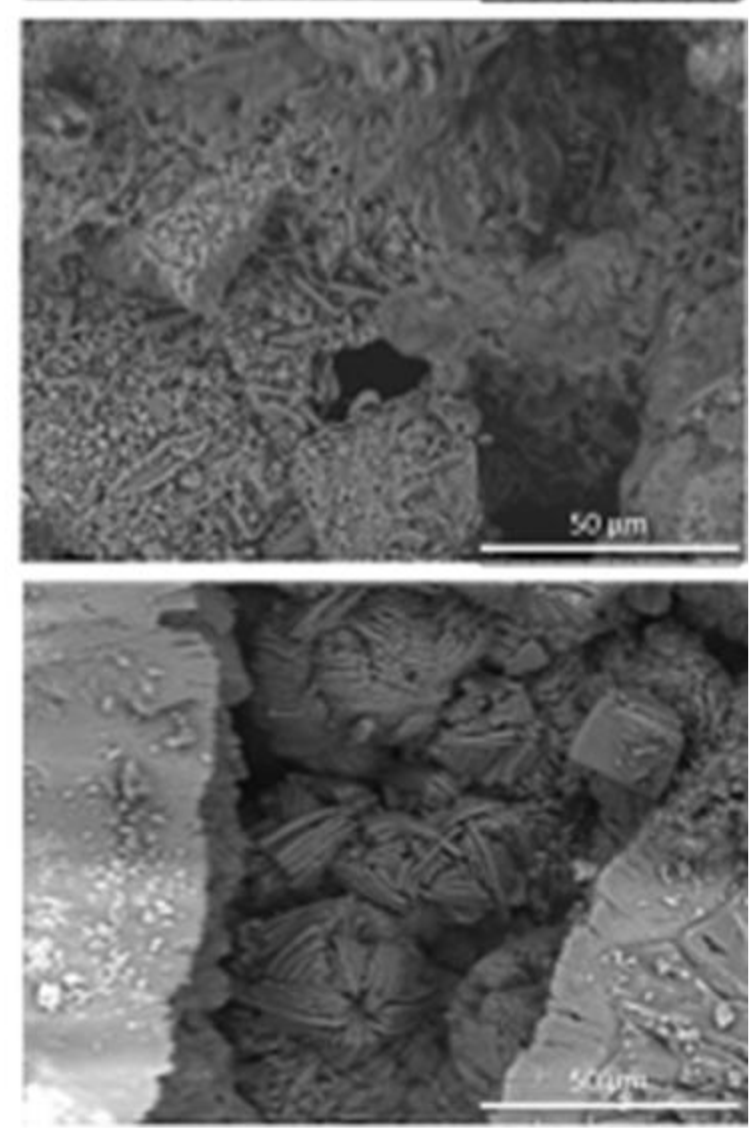

Fig. 8. SEM images of the surfaces of both stones after (a) $\mathrm{Na2SO} 4$, (b) $\mathrm{NaCl}$ and (c) SO2 tests.

Macroscopic and microscopic observations. Macro- scopically, thin crusts were formed around the slabs. Similarly to the Na2SO4 test, these crusts were easily removed in most of the slabs without dama- ging the stones. Neither strong colour change nor mechanical damage was observed.

Nevertheless, a homogeneous glossy layer covered the whole sur- face, produced, presumably, by small salt crystals.

Microscopically, on the Lutetian limestone, halite crystals were larger than thenardite crystals. These crystals grew up inside the pores, being easy to identify under a magnifying glass. On the external 
surface of the weathered samples, $\mathrm{NaCl}$ crystallized uniformly giving a 'sugar' gloss aspect to the samples.

Just as in the Na2SO4 tests, the surface of the Vernon chalk was partially coated with crystals of $\mathrm{NaCl}$. Halite crystals were smaller (c. $10 \mathrm{~mm}$ ) and thinner than in the Lutetian limestone (Fig. 8b). Halite crystals a few millimetres under the surface were rare. Their appearance and the salt distribu- tion on the surface of porous media were different for the two stones. According to Veran-Tissoires et al. (2012) and Eloukabi et al. (2013), this could be due to the spatial variation of drying flow and/ or to the structural heterogeneities of porous materials.

Strong acid atmosphere (SO2)

Colour. The parameter variations were not significant in the Lutetian limestone, and the variation of total colour DE* was less than 1 . In contrast, light- ness in the Vernon chalk decreased and there was a noticeable increase of hue ending up in a changing tone of yellow typical of sulphur exposure (Grossi et al. 2007; Vazquez \& Alonso 2010).

These variations produced a total colour change of 4 units, i.e. the change was above the visible threshold.

Roughness. Average roughness and maximum parameters increased in the Lutetian limestone. Kurtosis decreased below 3 , implying a transition to a platykurtic distribution, with a homogeneous distribution of discontinuities around the mean plane. Skewness reached almost zero, which meant that the distribution of the peaks and valleys became similar. The Vernon chalk showed a slight increase in all the roughness parameters, which is more important in the maximum peak; changes in kurtosis and skew- ness were not significant, which can be explained as an increase in roughness but with a constant height distribution.

Macroscopic and microscopic observations. Macro-scopically, the Lutetian limestone exhibited hardly any change, although even white spots were observed on the Vernon chalk.

Microscopically, on the external surface of the Lutetian limestone, circular particles of c. $100 \mathrm{~mm}$ diameter were visible. Looking closer into the pores, particles of different shapes (e.g. radial, flowershaped) could be observed, all sized between 20 and $50 \mathrm{~mm}$. Similar flower-shaped crystals were observed on the Vernon chalk. These flat crystals were combined with $100 \mathrm{~mm}$ prismatic crystals and $25 \mathrm{~mm}$-diameter ball crystals (Fig. 8c).

\section{Conclusions}

Although chalk is generally supposed to be less resistant than other limestones, some constructions of the Vexin region in France showed Vernon chalk in their basement walls and Lutetian limestone starting at a height of $1 \mathrm{~m}$. The petrography, phys- ical properties, especially hydric properties, and durability of both types of stone were assessed in order to understand this choice. 
The most significant differences between these two limestones concerned their pore spaces and water kinetics. Lutetian limestone showed almost double the porosity of Vernon chalk, as well as pores thirty times bigger. For this reason, water absorp- tion is extremely fast in Lutetian limestone, as pro- ved by free water absorption and capillary tests.

In relation to durability tests, salt efflorescences appeared earlier on the Lutetian limestone than on

the Vernon chalk. This is in agreement with their hydric properties and the higher capillary coefficient shown by the Lutetian limestone. Colour and roughness variations were assessed and the main variations took place after $\mathrm{Na} 2 \mathrm{SO} 4$ crystallization and $\mathrm{SO} 2$ exposure. With $\mathrm{Na} 2 \mathrm{SO} 4$ crystallization both stones turned a whitish colour because of thenardite that remained on the surfaces and within the pores. Even after soft brushing, the Lutetian lime- stone showed the higher quantity of salt, revealed not only by colour measurements and visual appearance, but also by an increase of average and maximal roughness parameters. This salt coating led to an increase of roughness with the appearance of more peaks and valleys on the surface, and consequently higher average roughness. In the Vernon chalk, roughness variation was more evident from an increase in peak height but was less evident from average parameters. $\mathrm{NaCl}$ crystallization formed a thin crust. After soft brushing, and measuring only those parts where this crust was easily removed, only slight changes in colour and roughness were observed in the Vernon chalk. However, this salt created a thin, transparent coating on both stones, which gave the surface a glossy finish. After SO2 exposure, the Lutetian limestone looked the same as the sound stone while the Vernon chalk exhibited white spots on its surface. The typical decay pro- duced by $\mathrm{SO} 2$ exposure of yellowing was not identifiable in the Lutetian limestone due to its orig-inal yellow-brownish colour. However, the Vernon chalk increased in hue after exposure indicating the expected yellowing. Roughness varied in both stones, showing greater changes in the Lutetian limestone.

The high porosity and water uptake of Lutetian limestone make it prone to salt crystallization and consequently susceptible to considerable decay as a building stone. Hence, the Vernon chalk is better for isolating walls from water coming up from the soil and avoiding massive salt crystallization. We can suppose that this is the reason for the special distribution of the two stones in monuments.

The authors would like to thank the Rocamat Society and the TERH Monuments Historiques for providing the samples used in this study, and Jean Badoux of the Cercle d'Etudes Vernonnais for his help in the biblio- graphic research about the Vernon chalk.

\section{References}

Angeli, M. 2007. Etude multie'chelle de la de'gradation des roches par la cristallisation de sels dans les re' seaux poreux. PhD thesis. Universite' de Cergy-Pontoise.

Angeli, M., Bigas, J. P., Mene' ndez, B., He' bert,R. \& David, C. 2006. Influence of capillary properties and evaporation on salt weathering of sedimentary rocks. In: Fort, R., Alvarez de Buergo, M., Gomez-Heras,M. \& Vazquez-Calvo, C. (eds) Heritage, Weathering and Conservation: Proceedings of the International Heritage, Weathering and Conserva- tion Conference (HWC-2006), 21-24 June 2006, Madrid, Spain. Taylor \& Francis/Balkema, Leiden, 253- 259. 
Angeli, M., Bigas, J. P., Benavente, D., Mene' ndez, B., He' bert,R. \&David, C. 2007. Salt crystallization in pores: quantification and estimation of damage. Environmental Geology, 52, 205- 213.

Angeli, M., Hebert, R., Mene' ndez, B., David,C. \& Bigas, J. P. 2010. Influence of temperature and salt concentration on the salt weathering of a sedimentary stone with sodium sulphate. Engineering Geology, 115, 193 - 199.

Arnold, A. 1976. Behaviour of some soluble salts in stone deterioration'. In: Skoulikidis, TH. (ed.) Proceedings of the 2nd International Symposium on the Deterio- ration of Building Stones, 27 September-1 October 1976. National Technical University of Athens, 27-36.

Baboux, J. 1997. Les carrie'res de Pierre de Vernon. Amis des Monuments et sites de I'Eure. Ville de Vernon, unpublished report.

Blanc, A. 1990. La pierre de Vernon (eure) et son utilis- ation dans les monuments. Carrie 'res et constructions en France et dans les pays limitrophes. In: JACQUELINE LORENZ \& PAUL BENOIT (eds) Proceedings of 115th Congre`s national des socie'te's savantes, April 9th - 12th 1990, 237-246.

Carmichael, R. S. 1989. Practical handbook of Physical Properties of Rocks \& Minerals. CRC Press, Boca Raton, Ann Arbor, Boston.

CEN (EUROPEAN COMMITTEE FOR STANDARDIZ- ATION) 1999. EN 1925: Natural stone test methods. Determination of water absorption coefficient by capillarity. CEN, Brussels.

CEN (EUROPEAN COMMITTEE FOR STANDARDIZ- ATION) 2002. EN 13919: Natural stone test methods. Determination of resistance to ageing by $\mathrm{SO} 2$ action in the presence of humidity. CEN, Brussels.

CEN (EUROPEAN COMMITTEE FOR STANDARDIZ- ATION) 2006. EN 1936: Natural stone test methods. Determination of real density and apparent density, and of total and open porosity. CEN, Brussels.

CEN (EUROPEAN COMMITTEE FOR STANDARDIZ- ATION) 2008. EN 13755: Natural stone test methods. Determination of water absorption at atmospheric pressure. CEN, Brussels.

CEN (EUROPEAN COMMITTEE FOR STANDARDIZ- ATION) 2009. EN ISO 105-J03: Textiles - Tests for colour fastness - Part J03 Calculation of colour differences. CEN, Brussels.

CEN (EUROPEAN COMMITTEE FOR STANDARDIZ- ATION) 2012. EN ISO 25178: Geometrical product specifications (GPS) - Surface texture: Areal - Part 2: Terms, definitions and surface texture parameters. CEN, Brussels.

Denecker, M. F. C. 2014. Le ro^ le des sulfates de sodium dans l'alte'ration des pierres du patrimoine bati: methodes indirectes d'identification pour l'approche experimentale. PhD thesis, Universite de Cergy- Pontoise.

Denecker, M., Vazquez, P., Menendez, B. \& Thomachot-Schneider, C. 2013. Utilisation combinee du calcaire lutetien et de la pierre de Vernon dans le patrimoine architectural: comparaison de leurs propriete's physiques et de leur durabilite'. XIV Congres franc, ais de sedimentologie, 4-8 November, 2013, Paris. 
Dessandier, D. 2000. Guide me'thodologique de se'lection des pierres des monuments en termes de durabilite' et compatibilite'. Bureau de Recherches Ge'ologiques et Minieres (BRGM)/RP-50137.FR.

Dewanckele, J., De Kock, T. et al. 2012. 4D imaging and quantification of pore structure modifications inside natural building stones by means of high resol- ution X-ray CT. Science of The Total Environment, 416, $436-448$.

Dewanckele, J., Boone, M. A. et al. 2013. Holistic approach of pre-existing flaws on the durability of two limestones. Science of the Total Environment, 447, 403-414.

Eloukabi, H., Sghaier, N., Ben Nasrallah,S. \& Prat, M. 2013. Experimental study of the effect of sodium chloride on drying of porous media: the crusty - patchy efflorescence transition. International Journal of Heat and Mass Transfer, 56, $80-93$.

Flatt, R. J. 2002. Salt damage in porous materials: how high supersaturations are generated. Journal of Crystal Growth, 242, $435-454$.

Fronteau, G., Moreau, C., Thomachot-Schneider,C. \& Barbin, V. 2010. Variability of some Lutetian building stones from the Paris Basin, from characteris- ation to conservation. Engineering Geology, $115,158-166$.

Gely, J. P. 2009. Le Lute'tien: une pe'riode charnie 're de l'histoire du Bassin parisien. Saga Information, 284, 6- 24.

Gomez-Heras,M. \&Fort, R. 2007. Patterns of halite ( $\mathrm{NaCl})$ crystallization in building stone conditioned by laboratory heating regimes. Environmental Geology, 52, 259- 267.

Grossi, C. M., Brimblecombe, P., Esbert,R. M. \& Alonso, F. J. 2007. Color changes in architectural limestones from pollution and cleaning. COLOR Research and Application, 32, 320-331.

Lasseur, E. 2007. La Craie du Bassin de Paris (Ce'noma- nien-Campanien, Cre' tace' supe'rieur). Se'dimentologie de facie's, stratigraphie se' quentielle et ge'ome' trie 3D. PhD thesis, Universite' de Rennes 1.

Moreau, C. 2008. Vieillissement naturel en milieu urbain de pierres calcaires hydrofuge'es: evaluation de la durabilite' des traitements et de leur impact sur le net- toyage. PhD thesis, Universite' de Reims Champagne- Ardenne.

Noe" I, P. 1970. Les carrieres franc, aises de pierre de taille. Socie'te' de diffusion des techniques du batiment et des travaux publics, Paris.

Perrier, R. 1993. Les roches calcaires de France. La Pierre en France. Mines et Carrie`res, les techniques, 75, $54-69$.

Rodriguez-Navarro,C.\&Doehne, E. 1999. Salt weath- ering: influence of evaporation rate, supersaturation and crystallization pattern. Earth Surface Processes and Landforms, 24, 191- 209.

Rodriguez-Navarro, C., Doehne,E. \&Sebastian,E. 2000. How does sodium sulfate crystallize? Implications for the decay and testing of building materials. Cement and Concrete Research, 30, $1527-$ 1534.

Takiyama, H., Otsuhata, T., Matsuoka, M. \& 1998. Morphology of $\mathrm{NaCl}$ crystals in drowning-out precipi- tation operation. Chemical Engineering Research and Design, 76, $809-814$. 
Vazquez, P. \& Alonso, F. J. 2010. SO2 exposure effect in monumental granitic stones. Proceeding in: IMA2010 Abstracts Volume, 6th volume of the Abstract Series of the journal Acta Mineralogica- Petrographica. International Mineralogical Association (IMA) conference: Bonds \& Bridges, $21-27$ August 2010, Budapest.

Vazquez, P., Carrizo, L., Fernandez,M. \& Alonso, F. J. 2010. Cambios en la superficie de rocas sedimentarias tras su exposicio' n a HNO3. Macla, 13, XXVII Reunio' n Sociedad Espan ₹ ola de Mineralog'́a (SEM), 16-18 September, Madrid, Spain, 219-220.

Vazquez, P., Luque, A., Alonso,F. J. \&Grossi,C. M. 2013. Surface changes on crystalline stones due to salt crystallization. Environmental Earth Sciences, 69, 1237-1248.

Veran-Tissoires, S., Marcoux,M. \& Prat, M. 2012. Salt crystallisation at the surface of a heterogeneous porous medium. EPL (Europhysics Letters), 98, 34005.

Winkler,E.M. \&Singer, P. C. 1972. Crystallization pressure of salt in stone and concrete. Geological Society of America Bulletin, 83, $3509-3513$. 